\title{
VIAJES CON SENTIDO: NOTAS PARA UNA HISTORIA DEL CINE ESPAÑOL ON THE ROAD
}

\author{
Santiago García Ochoa \\ Universidad de Santiago de Compostela/IES Manuel Chamoso Lamas
}

\begin{abstract}
RESUMEN
El presente artículo plantea el estudio de la evolución de la road movie en el cine español a través de tres etapas: carreteras franquistas (1955-1975), en la que aparecen algunos elementos del género pero la pervivencia de la dictadura impide que se fragüe una imagen de la carretera como espacio de búsqueda y reafirmación individual; carreteras hacia la democracia (19751982), periodo en el que se estrenan las primeras road movies; y carreteras democráticas (desde 1982 hasta hoy), que comprende la evolución del cine español on the road (boom a partir de la segunda mitad de los 90 y desarrollo en diferentes vías temáticas o subgéneros).

Palabras Clave: carretera, viaje, automóvil, road movie, cine espańol.
\end{abstract}

\section{TRAVEL WITH MEANING: NOTES FOR A HISTORY \\ OF SPANISH CINEMA ON THE ROAD}

\section{Abstract}

This article raises the study of the evolution of road movie in Spanish cinema through three phases: Francoist Roads (1955-1975), in which some elements of the genre appear but the survival of the dictatorship prevents the creation of an image of the road as a space for individual search and reaffirmation; Roads towards Democracy (1975-1982), period in which the first road movies are released; and Democratic Roads (from 1982 to nowadays), which includes the evolution of Spanish cinema on the road (boom from the second half of the $90 \mathrm{~s}$ and development in different thematic lines or subgenres).

KeYwords: road, trip, automobile, road movie, Spanish cinema. 


\section{INTRODUCCIÓN}

Aunque algunos autores consideran la road movie como un fenómeno transnacional unido al desarrollo de la movilidad ${ }^{1}$, la mayoría coinciden en situar sus orígenes en EE. UU. a finales de los 60, a partir de una serie de elementos preexistentes típicamente norteamericanos: el espíritu renovador de la extensión de la frontera y la literatura (Mark Twain o Jack London) y el cine (el wéstern) desarrollados en torno a él; la highway culture fraguada tras la II Guerra Mundial y la contracultura, a partir de la novela $O n$ the Road, de Jack Kerouac, publicada en 1957, cuyo éxito inmediato convirtió a la generación beat en un fenómeno de masas.

La road movie posee una poética propia basada en la estructura narrativa en torno al desplazamiento por carretera; el empleo de unos recursos técnicos concretos (camera car); el sentido metafórico del viaje, entendido como iniciación o aprendizaje; y su capacidad para retratar la sociedad del momento. Lógicamente existen películas norteamericanas cuya estructura se articula en torno al desplazamiento de los protagonistas anteriores a la década de los 60: It Happened One Night (Sucedió una noche), Frank Capra, 1934 y The Grapes of Wrath (Las uvas de la ira), John Ford, 1940, entre las más citadas. Según Frasca proceden fundamentalmente de cuatro géneros: wéstern, comedia sofisticada, cine negro y biker-movie ${ }^{2}$. En cualquier caso estas películas todavía no poseen la poética propia del género, que se configura durante la fase conocida como New Hollywood (1967-1975), a partir de la influencia de los nuevos cines europeos (decisiva para la configuración de la nueva estética, que se apoyó en el rodaje en escenarios naturales gracias al uso del camera car $)^{3}$, en una serie de títulos emblemáticos como Bonnie and Clyde (Bonnie y Clyde), Arthur Penn, 1967, Easy Rider (Easy Rider. En busca de mi destino), Dennis Hopper, 1969, Two Lane Blacktop (Carretera asfaltada en dos direcciones), 1971 o Vanishing Point (Punto limite: cero), Richard C. Sarafian, 1971.

Existe una abundante bibliografía sobre la road movie. Bastantes autores dedican uno o varios capítulos al desarrollo del género fuera de EE. UU., como Steven Cohan e Ina Rae Hark (1997) (eds.), The Road Movie Book (New York, Routledge, 1997), Jack Sargeant y Stephanie Watson (eds.), Lost Highways. An Illustrated History of Road Movies (London, Creation Books, 1999) o David Laderman, Driving Visions. Exploring the Road movie (Austin, University of Texas, 2002), pero ninguno analiza el caso español, ni siquiera a través de algún título emblemático. La guía de Jason Wood 100 Road Movies (London, British Film Institute, 2007) no incluye ninguna película española, salvo tres coproducciones: Professione: reporter (Michelangelo An-

1 Puede destacarse el trabajo de Orgeron, Devin (2008): Road Movies. From Muybridge and Mèlies to Lynch and Kiarostami, New York, Palgrave Macmillan.

2 FrasCa, Giampiero (2001): ROAD MOVIE. Immaginario, genesi, struttura e forma del cinema americano on the road, Torino, UTET.

${ }_{3}$ Con películas como À bout de souffle (Al final de la escapada, Jean-Luc Godard, 1959), Il sorpasso (La escapada, Dino Risi, 1962), Pierrot le fou (Pierrot el loco, Jean-Luc Godard, 1965) o Stress es tres tres (Carlos Saura, 1968). 
tonioni, 1975), Guantanamera (Tomás Gutiérrez Alea y Juan Carlos Tabío, 1995) y Bombón, el perro (Carlos Sorín, 2004), ésta última curiosamente identificada como íntegramente española («Spain, 2004»).

El estudio de la road movie en el cine español es una línea de investigación casi inédita que apenas se ha desarrollado en algunos artículos, tanto a través del análisis de películas concretas como Airbag (Juanma Bajo Ulloa, 1995) ${ }^{4}$, Vámonos, Bárbara (Cecilia Bartolomé, 1978) ${ }^{5}$ o Stress es tres tres (Carlos Saura, 1968) películas con protagonismo femenino dirigidas por mujeres ${ }^{7}$; o intentando abarcar el fenómeno de una forma global ${ }^{8}$. El libro de Jorge Pérez Cultural Roundabouts: Spanish Film and Novel on the Road (Lewisburg, Bucknell University Press, 2011), que estudia el road genre en la literatura y el cine, es la aproximación más completa y rigurosa al tema que nos ocupa publicada hasta la fecha. Su autor parte de la metáfora de la rotonda, que da título a la obra: «... I propose to conceptualize the road genre in Spain as a cultural roundabout in which cultural traffic flows in different directions, allowing multiple points of entry and exit»?.

En Cultural Roundabouts se analizan Elpuente (Juan Antonio Bardem, 1977) y Vámonos, Bárbara como ejemplos que conceptualizan la metáfora de la carretera como vía indirecta (rotonda en vez de autopista) hacia la democracia; Los managers (Fernando Guillén Cuervo, 2006), como parodia de la road movie; Kasbah (Mariano Barroso, 2000), como ejemplo del cruce de fronteras; y, finalmente, Fugitivas (Miguel Hermoso, 2000), que ilustra el triunfo de la mujer al volante en un género tradicionalmente masculino.

${ }^{4}$ Induráin Eraso, Carmen (2005): «Riding on divergent but similar roads: Airbag or the Spanish experience of the American road movie», Estudios Ingleses de la Universidad Complutense, vol. 13, pp. 107-121.

5 PÉRez, Jorge (2008): «Spanish Women Behind the Wheel: Gendering the Transition to Democracy in Vámonos, Bárbara», Revista de Estudios Hispánicos, vol. 42, núm. 2, pp. 215-36.

${ }^{6}$ Lie, Nadia (2011): «Saura y el género road movie: análisis de Stress es tres, tres», en LEfere, Robin (ed.), Carlos Saura: una trayectoria ejemplar, Madrid, Visor, pp. 29-45; y Duprat DE Montero, Arnaud (2016): «Carlos Saura’s Stress es tres, tres» (1968): «A New Spanish Cinema with French and American Influences?», en Oliete-Aldea, Elena; Oria, Beatriz y Tarancón, Juan A. (eds.), Global Genres, Local Films: The Transnational Dimension of Spanish Cinema, New York, Bloomsbury, pp. 89-101.

7 PéRez, Jorge (2013): «La road movie. Directoras españolas al volante: La road movie como viaje de concienciación ética», en ZeCCHI, Bárbara (coord.), GYNOCINE: teoría de género, filmología y praxis cinematográfica, Zaragoza, Universidad de Zaragoza, pp. 129-59.

${ }^{8}$ PoHL, Burkhard (2007): «Rutas transnacionales: la road movie en el cine español», Hispanic Research Journal, vol. 8, num. 1, pp. 53-68; Induráin Eraso, Carmen (2016): «The Transnational Dimension of Contemporary Spanish Road Movies», en Oliete-Aldea, Elena; Oria, Beatriz y Tarancón, Juan A. (eds.), op. cit., pp. 141-55; y García Ochoa, Santiago (2016): «La road movie como modelo transnacional y su presencia en el cine espańol: marco metodológico y principales aportaciones», Boletín de Arte, núm. 37, pp. 79-88.

9 PÉrez, Jorge (2011): Cultural Roundabouts: Spanish Film and Novel on the Road, Lewisburg, Bucknell University Press, p. 12. 
El estudio del cine español on the road resulta muy poco transitado seguramente porque obliga al complejo análisis de la hibridación entre lo nacional (cine español) y lo importado (on the road), por ser la road movie un género sin apenas tradición dentro de nuestras fronteras (aunque con raíces europeas e incluso españolas: piénsese en la novela picaresca o el Quijote); de ahí que los especialistas hayan recurrido a los estudios transnacionales para abordarlo ${ }^{10}$.

\section{UNA HISTORIA DEL CINE ESPAÑOL ON THE ROAD}

Ninguno de los trabajos académicos publicados hasta la fecha aborda la presencia de la road movie en el cine español desde un enfoque exclusivamente diacrónico. Casi todos ellos se centran en títulos concretos, preferentemente de finales del siglo xx y principios del xxI. Nuestro objetivo aquí es definir y caracterizar unas etapas (tres) que permitan estudiar la evolución del cine español on the road de forma sistemática:

a) Carreteras franquistas (1955-1975). Coincide con el final de la autarquía y el segundo franquismo, y permite constatar la incompatibilidad de la imagen de la carretera como espacio de búsqueda con la dictadura, aunque durante los años 50 se percibe la influencia de dos de los géneros del cine norteamericano que, según Frasca, prefiguran la road movie: la comedia sofisticada y el cine negro.

b) Carreteras hacia la democracia (1975-1982). Coincide con la Transición y es el periodo en el que aparecen las primeras road movies: iJo, papá! (Jaime de Armiñán, 1975), El alijo (Ángel del Pozo, 1976), El puente, Vámonos, Bárbara, A contratiempo (Óscar Ladoire, 1981) y Corridas de alegría (Gonzalo García Pelayo, 1981).

c) Carreteras democráticas (1982 a la actualidad). Coincide con la España democrática y comprende la evolución del cine español on the road, que experimenta su boom a partir de la segunda mitad de los 90 y se desarrolla en diferentes vías temáticas o subgéneros.

${ }^{10}$ Un análisis más detenido de la bibliografía académica sobre el tema, así como del marco metodológico de los estudios transnacionales aplicado a la road movie, puede verse en GARCÍA OCHOA, Santiago (2016), op. cit. 


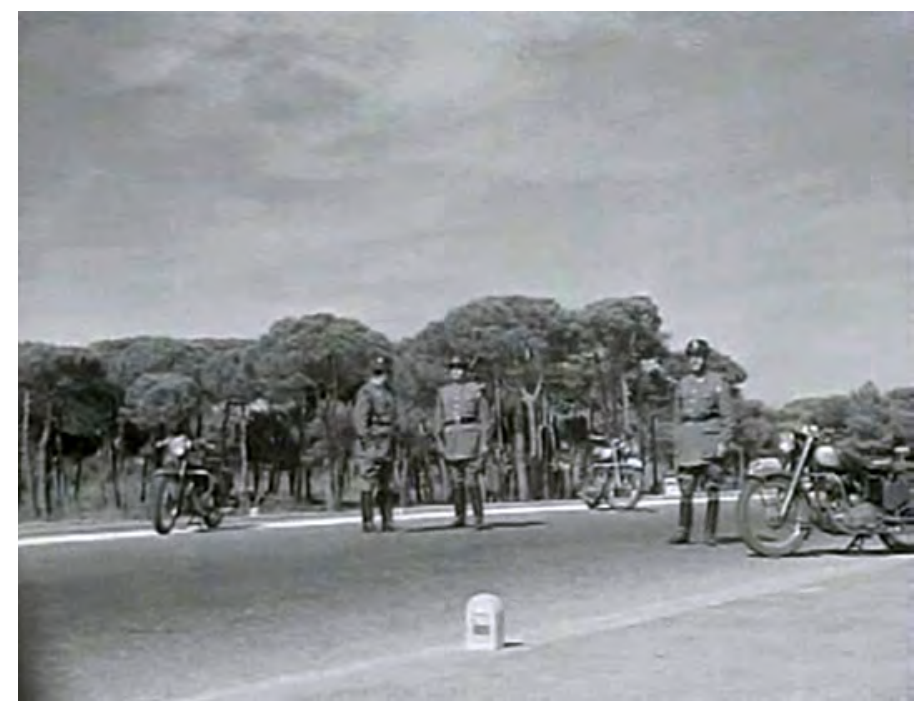

Fig. 1. Despliegue de la guardia civil en Camino cortado.

\subsection{Carreteras franquistas}

Durante esta etapa los viajes por carretera aparecen en las películas en forma de episodios más o menos aislados; rara vez la narración de un filme se estructura, de principio a fin, en torno a uno de estos desplazamientos. Además, la carretera suele presentarse como un espacio de uso restringido reservado a ciertas minorías.

La decidida intervención de los cuerpos de seguridad del Estado (policía y guardia civil) en el cine negro de los 50, siempre capaces de frustrar cualquier tentativa de huida de los marginados sociales abocados a la delincuencia, incluso cuando éstos viajan por espacios abiertos con la esperanza de alcanzar la frontera, como en Camino cortado (Ignacio F. Iquino, 1955) y Carretera general (José María Elorrieta, 1956), contribuyó en buena medida a consolidar esta imagen de las carreteras franquistas. Emblemática resulta la cinta de Iquino, en la que los malhechores de turno terminan desviándose a un pueblo abandonado (su camino cortado) debido a la apabullante presencia de guardias civiles en la carretera (luego descubrirán que no estaban allí por ellos, sino por la inauguración de un embalse) (fig. 1).

En Muerte de un ciclista (1955), Juan Antonio Bardem construye una alegoría sobre la lucha de clases a partir del atropello de un ciclista: el coche representa a la burguesía adinerada; la bicicleta, a la clase obrera ${ }^{11}$, y la carretera funciona como el

${ }^{11}$ De hecho, el cineasta hurta al espectador, de forma intencionada, las imágenes del ciclista moribundo, y sólo le permite ver, en la parte inferior del cuadro, la bicicleta rota. En este sentido 
espacio jerarquizado en el que se dirimen las diferencias entre ambas (sabemos por la conversación de unos policías que los atropellos de ciclistas eran bastante frecuentes).

El hombre que viajaba despacito (Joaquín Romero Marchent, 1957) recrea las penurias del viaje en clave humorística ${ }^{12}$, abusando de las situaciones absurdas ideadas y protagonizadas por un Gila soldado que cambia contantemente de medio de transporte (tren, camión, coche, incluso va andando) para conjurar la maldición de una gitana y poder llegar sano y salvo hasta su hijo recién nacido (al final descubrirá que son tres en vez de uno ${ }^{13}$. En el polo opuesto se encuentran ciertas películas de temática turística que presentan a extranjeros viajando por una España idílica, como Aventura para dos (Spanish Affair, Don Siegel y Luis Marquina, 1957) y Luna de miel (Honeymoon, Michael Powell, 1959). En 1950 se había aprobado el Plan de Modernización de Carreteras y a los pocos años, en 1953, el Plan Nacional de Turismo (primer programa de actuaciones para este sector), que con el objetivo de captar las vacaciones de millones de extranjeros al año organizaba la oferta turística en cuatro modalidades: turismo histórico-artístico y folclórico (el de Luna de miel), turismo de descanso, turismo deportivo y turismo de negocios (el de Aventura para dos) ${ }^{14}$.

Jesús Franco arremete contra la visión (u)tópica del país que proporcionaba este tipo de cine propagandístico en su atípica y heterodoxa ópera prima: Tenemos 18 años (1959), en la que dos jóvenes españolas recuerdan su viaje de Madrid a Andalucía en un viejísimo y destartalado vehículo (fig. 2), que contrasta con los lujosos automóviles de Aventura para dos y Luna de miel. La presencia de mujeres viajando solas a finales de los 50 era algo escandaloso, más todavía si se tiene en cuenta que se trata de dos chicas de 18 años que maduran durante un viaje en el que sus principales experiencias son sus encuentros con un atracador y un psicópata asesino. Un periplo que funciona en sentido contrario al del célebre libro de lectura escolar Viaje infantil (publicado por vez primera en 1892 y modificado posteriormente en

conviene tener en cuenta la vinculación intertextual de la película con Ladri di biciclette (Ladrón de bicicletas, Vittorio De Sica, 1948), de clara ideología comunista.

${ }^{12}$ La precariedad presente en la diégesis se ve sin duda potenciada por los escasos medios de producción de que dispuso su director: «... en una escena en que el camión donde va el protagonista tenía que colisionar con un tren, [Santos] Alcocer [el productor] me dijo El camión es alquilado, como se le roce un poco el parachoques estamos perdidos. Asi que a ver lo que haces. Yo respondí Hombre, es que algo tendrá que rozarse y él contestó Imposible. Por lo tanto tuvimos que apoyar el camión sobre el tren y rodar el momento marcha atrás». Aguilar, Carlos (1999): Joaquín Romero Marchent. La firmeza del profesional, Almería, Diputación de Almería, p. 26.

${ }^{13}$ Entre las situaciones más disparatadas merecen destacarse las siguientes: un aeroplano se estrella justo después de que Gila se baje; el ferrocarril en el que viaja se detiene para que arreglen las vías y de inmediato un camión sin frenos choca contra su vagón; en el último tren, el protagonista renuncia a seguir sacando aleatoriamente por orden los palos de una baraja espańola porque ha llegado a su destino. El mismo viaje tendría que haber durado una jornada en vez de tres, y tres son los hijos que se encuentra Gila en vez de uno.

${ }_{14}$ Del Rey Reguillo, Antonia y Nieto Ferrando, Jorge (2013): «Transiciones del turismo en el cine español de ficción de los años cincuenta y sesenta", Actas del Congreso Internacional Hispanic Cinemas: En Transición. Cambios históricos, politicos y culturales en el cine y la televisión, Madrid, Universidad Carlos III/Ministerio de Economía y Competitividad, pp. 991-992. 


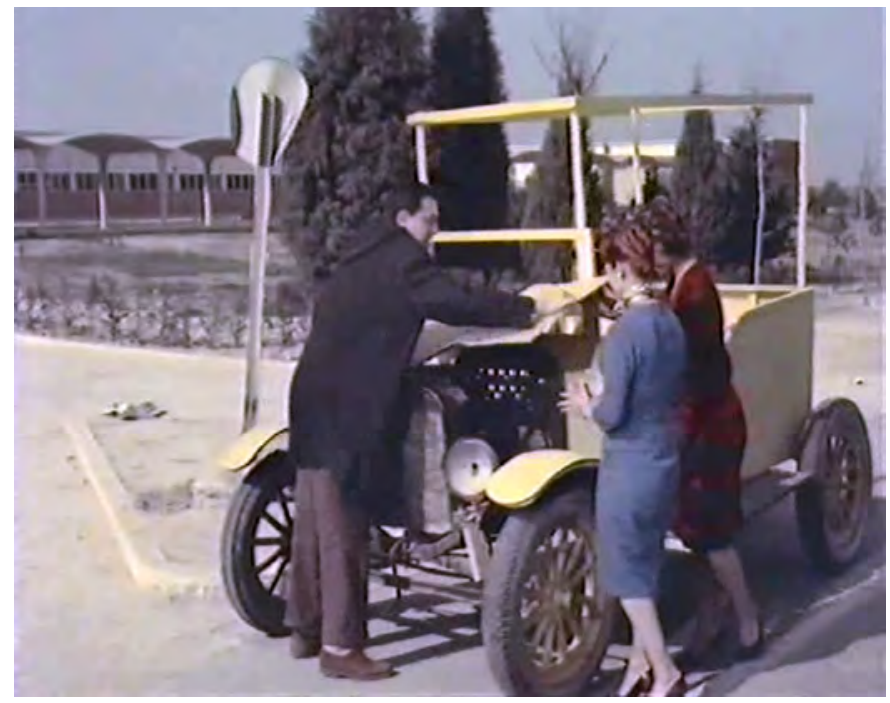

Fig. 2. El viejo automóvil amarillo de Tenemos 18 años.

innumerables ediciones), en el que Santiaguito, tras obtener el primer premio en los exámenes escolares, era obsequiado por su padre con un viaje de formación por todas las regiones españolas; libro de lectura que, además, acababa de conocer su versión femenina, escrita por el inspector de enseñanza primaria Antonio J. Onieva: Carmencita de viaje (Burgos, Hijos de Santiago Rodríguez, 1958) ${ }^{15}$. En este caso, la niña viajaba acompañada de su madre y del chófer del padre «descubriendo muchas de las cosas que más le interesan a una mujer»: los bordados de la Alberca, la alfarería de Extremadura, las porcelanas andaluzas, la clase de cocina, etc. ${ }^{16}$.

Al denegarle casi siempre al español medio la posibilidad de conducir su propio automóvil, la comedia predesarrollista también alimentó la imagen de la carretera como espacio de uso restringido (reservado a las clases dirigentes y a los extranjeros), incluso en Ya tenemos coche (Julio Salvador, 1958), film propagandístico de la salida al mercado del Seat 600 en $1957^{17}$, hecho que marca, de forma simbólica, la entrada de España en la producción y utilización del automóvil de turismo; y digo simbólica porque «... había que esperar hasta cuatro años para conseguirlo, a

15 Aprobado por el Ministerio de Educación Nacional el 30 de julio de 1959.

16 En Tenemos 18 años Franco llevó al extremo el planteamiento de El hombre que viajaba despacito, en la que había sido compositor de la música y ayudante de dirección. No en vano la película vio retrasado su estreno hasta 1967.

17 Aunque en el primer desarrollo argumental de Pedro Masó, fechado en febrero de 1956, el protagonista adquiere un Fiat de importación (Biblioteca Nacional, Sala Cervantes, T/43855). 


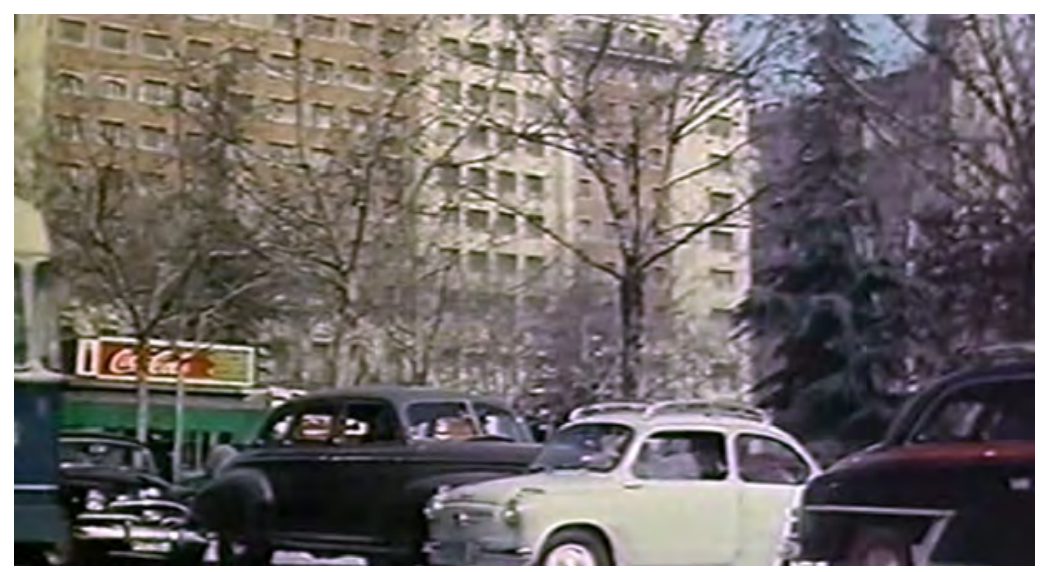

Fig. 3. Una peculiar forma de aparcar en Ya tenemos coche.

no ser que uno fuera el General Muñoz Grandes (que compró para su hijo el primer 600 que salió de fábrica) o tuviera un buen enchufe» ${ }^{18}$. En consonancia con ello, el director y su cuadro de guionistas construyen un discurso ambiguo (el título aparece entrecomillado en los créditos), más disuasorio que alentador, acerca de las ventajas que ofrece el automóvil ${ }^{19}$. La claridad expositiva facilita su lectura, que puede resumirse como sigue:

a) Beneficios que supone tener un coche (antes de poseerlo): don José (Umberto Spadaro) podrá prescindir de las incomodidades del transporte urbano, llevar a su familia al campo los fines de semana, a sus amigos al fútbol, y al equipo de fútbol de su hijo a los partidos.

b) Sacrificios que supone adquirirlo: principalmente económicos, pues, a pesar de la aportación de la suegra, la familia debe renunciar a sus vacaciones. A ello hay que añadirle el examen de conducir y el viaje a Barcelona para recogerlo, pues, si no, tardarían en dárselo más de un mes.

c) Problemas de tener coche: accidentes, multas, averías, dificultades para aparcar en pleno centro de Madrid (fig. 3), la obligación de llevar a la familia a todas partes (de hecho, ahora madruga más que cuando cogía el autobús), tener que dejarlo prestado (hasta su secretaria y su jefe se lo piden) y gastos, muchos gastos.

18 Sánchez Vidal, Agustín (1990): Sol y sombra, Barcelona, Planeta, pp. 168-169.

19 La Junta de Censura no puso pega alguna al contenido del film, considerando que abordaba una "problemática actual» (;!) en clave humorística, como escribió alguno de los vocales (Archivo General de la Administración, Sección Cultura, Exp. 36/03672). 


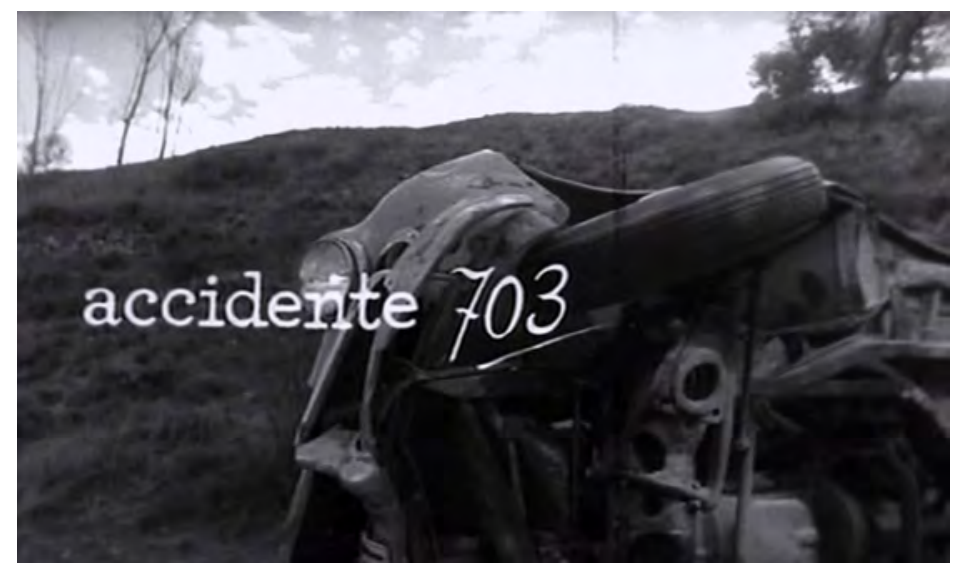

Fig. 4. El terrible siniestro que abre Accidente 703.

d) Relevo generacional: harto de historias, don José entrega a su hija el coche como regalo de bodas, entonces su vida recupera el equilibrio. «Los jóvenes necesitan ir más deprisa que nosotros», confesará, con un punto de nostalgia, a su amigo, que también se ha desprendido de su automóvil.

El mensaje está bien claro: el espańol medio de los 50, cabeza de una familia acomodada, no está todavía preparado para poseer un coche. Aunque la realidad era otra bien distinta: la incipiente industria del automóvil no podía abastecer toda la demanda. Sólo seis de cada 1000 españoles tenían coche en $1958^{20}$, lo que convierte a don José en un auténtico pionero. Los demás debían conformarse, como mucho, con conducir una motocicleta o un microcoche, Biscúter y similares, como hacen los personajes interpretados por Gila en Historias de la Feria (Francisco Rovira Beleta, 1958), Analía Gadé en La vida por delante (Fernando Fernán Gómez, 1958) o Tony Leblanc y Antonio Ozores en Los tramposos (Pedro Lazaga, 1959).

Accidente 703 (José María Forqué, 1962) es, sin duda, el mejor testimonio fílmico del estricto control del tráfico ejercido por la dictadura franquista a partir del nacimiento de la Dirección General de Tráfico en 1959. El film, claramente propagandístico, reconstruye un expediente ficticio de la DGT (el número 703): se abre con el siniestro presentado en todo su dramatismo (fig. 4) y luego retrocede en el tiempo para mostrarnos las circunstancias previas y las personas implicadas.

Durante la década de los 60 la industria del automóvil experimenta el mayor crecimiento dentro del sector industrial, que, a su vez, crece muy por encima de

${ }^{20}$ Fundación FOESSA (1966): Informe sociológico sobre la situación social de España, Madrid, Euramérica, p. 279. 


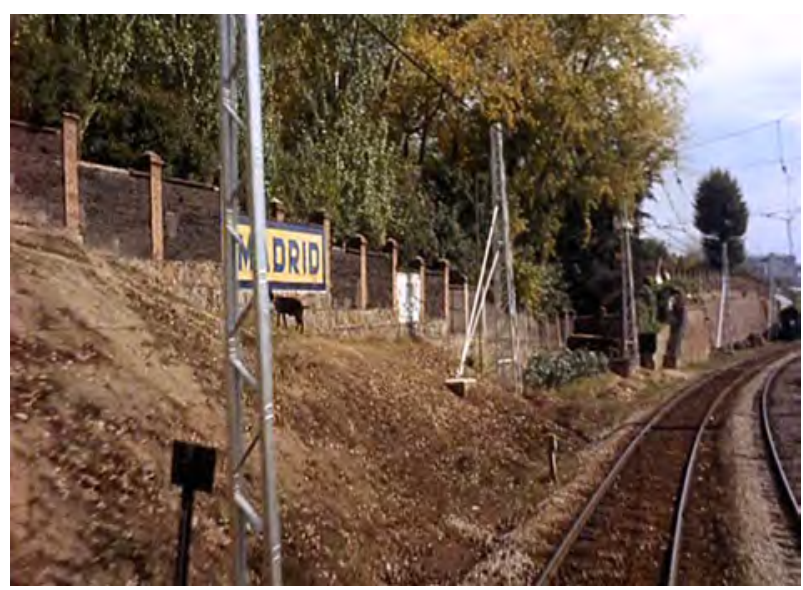

Fig. 5. El punto de vista de Tomasa desde un tren en marcha al inicio de Sor Citroen.

la economía en su conjunto. El desarrollismo incrementó de forma notable la disponibilidad económica del español medio, modificando sus patrones de consumo. Los primeros electrodomésticos (televisor, lavadora, frigorífico) se erigen como los productos simbólicos por antonomasia de la primera mitad de los 60, mientras el coche lo será de la segunda: en 1966 la producción de automóviles superó por primera vez a la demanda ${ }^{21}$.

Sor Citroen (Pedro Lazaga, 1967) es un fiel reflejo del contradictorio discurso oficial de los 60, que presentaba esta modernización económica como un logro de las estructuras políticas y sociales vigentes, o lo que es lo mismo, que invitaba a los españoles a motorizarse, pero les denegaba el uso de la carretera como un espacio abierto, ya no tanto en un sentido físico (en 1967 se redacta el Programa Nacional de Autopistas Españolas), sino metafórico (movilidad social, apertura política en paralelo a la económica) ${ }^{22}$. El tránsito entre la tradición (el viaje en tren) y la modernidad (el viaje en coche) aparece sublimado en la figura de Tomasa (Gracita Morales), que arrastra el trauma de haber renunciado a sus ilusiones infantiles de ser ferroviaria (la película comienza con una secuencia que recrea su hipotético punto de vista desde un tren en marcha [fig. 5]), y no puede aprobar el examen de conducir

${ }^{21}$ Servicio de Estudios Económicos del Banco Urquijo (1970): Evolución a largo plazo de la industria del automóvil en España, Madrid, Banco Urquijo, pp. 32-33.

${ }^{22}$ No debemos menospreciar la importancia del automóvil, artefacto que proporcionaba una ilimitada movilidad personal y familiar, como sustitutivo de la verdadera libertad personal (política). El coche aparece además estrechamente relacionado con la emigración y el turismo, los dos emblemas de la «España móvil», de fronteras abiertas. PAvlovic, Tatiana (2004): «España cambia de piel (1954-1964)», Res publica, núms. 13-14, pp. 284-285. 
al estar bloqueada por un sentimiento de culpa (ya que abandonó a su padre para tomar los hábitos). Será la llegada de dos hermanitos huérfanos que han de vivir separados (la nińa con las monjas, el niño con los curas) la que decida el conflicto entre tradición y modernidad: el $2 \mathrm{CV}$ sirve para acercarlos, salvar su vida en dos ocasiones (borrando la imagen traumática de la muerte de sus padres en un terrible choque nocturno contra un camión) y, finalmente, para llevarlos a vivir con el padre de la monja (la vieja deuda afectiva queda saldada), aunque esto le cueste a Tomasa el traslado a Bilbao.

Sor Citroen es una monja joven y rebelde que al incorporar el coche al convento sigue el discurso oficial del desarrollismo («andando todo el día pedimos en 20 casas, con el coche pediremos en 100, así aumentaremos la productividad, ¡hay que motorizarse!»), de la misma forma que su conducta encaja a la perfección con los roles asignados por el régimen franquista a la mujer, que en esos años, según el código civil vigente, seguía plenamente supeditada a la figura masculina: el film se abre con un flashback en el que se relata el abandono del padre para entregar su vida a Dios (el Padre), mientras que se cierra cuando la joven consigue restituir la deuda contraída con su progenitor.

Dos películas de Carlos Saura y una serie de televisión de Mario Camus aportan los elementos esenciales de base (asfaltan la carretera) para el nacimiento del cine español on the road en el periodo siguiente: Stress es tres tres (1968), La prima Angélica (1973) y Los camioneros (TVE, 1973-1974).

Stress es tres tres puede considerarse como uno de los títulos emblemáticos de los nuevos cines europeos que prefiguran la road movie: posee una estructura episódica marcada por las paradas durante un desplazamiento por carretera de Madrid a Almería, con protagonismo muy marcado del viaje y rodaje en escenarios naturales (lo cual obligó al empleo de equipos ligeros y camera car); pero sigue glosando la imagen de la carretera como especio de uso restringido, ya que los tres protagonistas pertenecen a la clase privilegiada de la burguesía franquista.

La prima Angélica pone en la carretera a un personaje de ideología totalmente contraria al régimen: Luis (José Luis López Vázquez), un editor cuarentón que viaja de Barcelona a Segovia para inhumar los restos de su madre en el panteón familiar. Durante el viaje y su estancia en la ciudad castellana comienzan a aflorar los recuerdos de una infancia represiva que coincidió con el inicio de la guerra civil. Todo parece indicar que Luis nunca podrá abandonar Segovia (identificada para él con su pasado traumático): tras la inhumación llega a ponerse en la carretera pero da la vuelta; al final de la película, durante un inocente paseo, recuerda la paliza que le propinó su tío cuando de niño intentó escaparse en bicicleta con su prima.

En Los camioneros, Sancho Gracia interpreta a Paco, un transportista madrileño que viaja a lo largo y ancho de la geografía española, siempre con un compañero diferente (fig. 6). Paco encarna el estereotipo del camionero ligón y los roles que se muestran en la serie son muy representativos de la buena moral franquista del momento. De todas maneras no debemos olvidar que el universo machista de los camioneros (la pareja masculina al volante) es un rasgo distintivo de la road movie norteamericana (buddy movie), como lo es también el predominio de los exteriores y los planos de los vehículos por la carretera. 


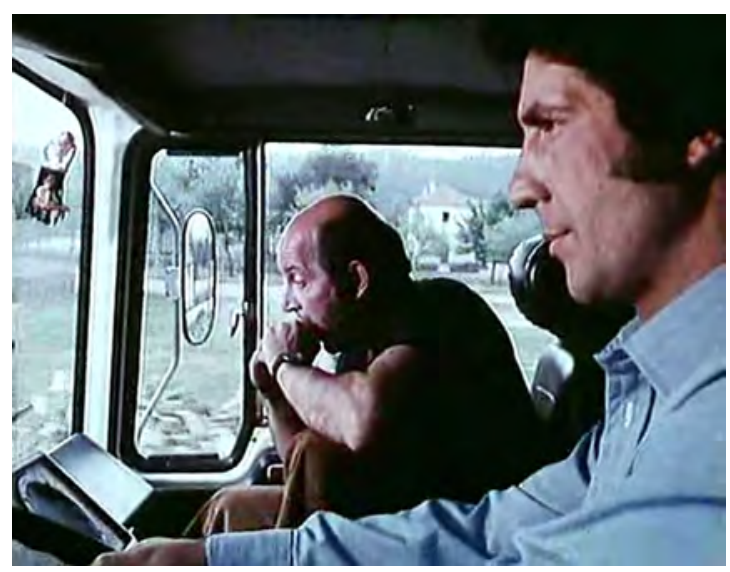

Fig. 6. Paco con su compañero de turno en un episodio de Los camioneros.

\subsection{Carreteras hacia la democracia}

La configuración de la carretera como un espacio de búsqueda y reafirmación individual y colectiva se produce durante la transición a la democracia (1975-1982) en seis títulos emblemáticos: iJo, papá! (Jaime de Armiñán, 1975), El alijo (Ángel del Pozo, 1976), El puente (Juan Antonio Bardem, 1977), Vámonos, Bárbara (Cecilia Bartolomé, 1978), A contratiempo (Óscar Ladoire, 1981) y Corridas de alegría (Gonzalo García Pelayo, 1981).

iJo, papá!, estrenada apenas un mes después de la muerte de Franco, aborda el peculiar viaje ideado por un próspero comerciante vigués, Enrique Seoane (Antonio Ferrandis): se trata de recrear el itinerario de su regimiento durante la guerra civil (entre Vigo y Vinaroz) con la intención de rememorar las gestas de la contienda (lógicamente él luchó en el bando de los sublevados) haciendo partícipe a su familia. Nada más lejos de la realidad, porque aunque todos viajan en el mismo automóvil, conducido por Enrique, durante el periplo su mujer y su hija mayor se definen como individuos con intereses propios cuyo rumbo ya no es controlado por el marido/padre.

El alijo está protagonizada por una pareja masculina (male buddy couple), el veterano Paco (Fernando Sancho) y el joven Curro (Juan Luis Galiardo), dos camioneros que trasladan a unos emigrantes portugueses sin papeles hasta la frontera con Francia. La introducción del elemento humano en sustitución de los habituales cargamentos de tabaco, un grupo de personas de diferentes sexos y edades que viajan en difíciles condiciones (escondidos entre ovejas) a la busca de una vida mejor, funciona en paralelo al periplo y el estrechamiento de la relación entre los dos camioneros, cuyo futuro también está en el aire.

El puente recrea las aventuras de Juan (Alfredo Landa), un mecánico que aprovecha el fin de semana para viajar en su moto de Madrid a Torremolinos y durante el trayecto entra en contacto con gentes muy diversas a la vez que toma 


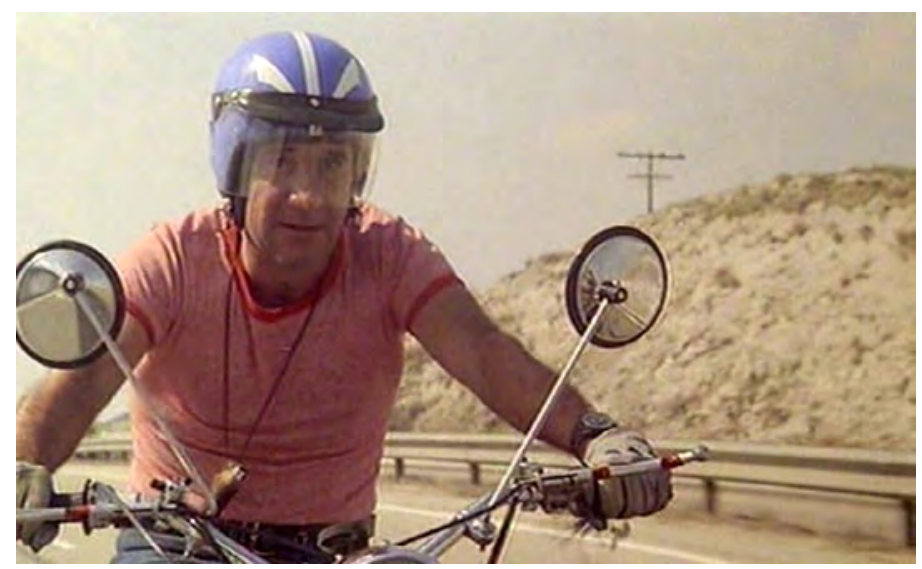

Fig. 7. Juan de camino a Torremolinos en El puente.

conciencia de los cambios que se están produciendo en Espańa en los inicios de la Transición (la película se rodó durante el verano de 1976). El viaje adquiere un importante protagonismo y los planos de Juan conduciendo por la carretera mientras reflexiona o habla con su moto se multiplican (fig. 7), así como los del resto de los vehículos en los que en algún momento viaja el personaje, todos ellos rodados en exteriores, como corresponde a la estética de la road movie. A su vuelta (el martes, tras el puente), Juan cambia su negativa inicial a participar en el sindicato de la empresa por una emotiva llamada a la solidaridad dirigida a sus compañeros de trabajo.

En Vámonos, Bárbara Amparo Soler Leal encarna a Ana, una mujer madura, publicista en Barcelona, que decide repentinamente abandonar a su marido y se marcha de vacaciones a la costa con su hija Bárbara (Cristina Álvarez), usurpándole su Mercedes (el Ford Fiesta de Ana se estropea). De nuevo adquieren gran importancia los encuentros, en este caso para lanzar un alegato en favor de la liberación de la mujer. Al final, madre e hija inician el regreso a Barcelona (ya en el Ford Fiesta de Ana) acompañadas de Iván (Iván Tubau), la nueva pareja de Ana, pero la actitud de éste (similar a la del marido y padre) las convence enseguida de la necesidad de afrontar su viaje (la separación) solas, y lo dejan tirado en una gasolinera.

En A contratiempo, Félix Ortiz (Óscar Ladoire) es un director de cine en crisis que viaja a Galicia para localizar exteriores y entabla una relación especial que borra las diferencias generacionales con Clara (Mercedes Resino), una muchacha de quince años. El peculiar y escéptico Félix Ortiz es una prolongación del Matías de Ópera prima (Fernando Trueba, 1980), ambos encarnan el arquetipo del individualista pasota desencantado (Ladoire), de bajón tras la euforia inicial que supuso el final de la dictadura. El viaje por carretera se convierte en el equivalente (post)moderno del flâneur, del deambular sin rumbo, que va también unido al draguer, al flirteo.

Corridas de alegría es la road movie más contracultural del cine español, el auténtico Easy Rider hispano, en el que reaparecen la liberación sexual, las drogas y 


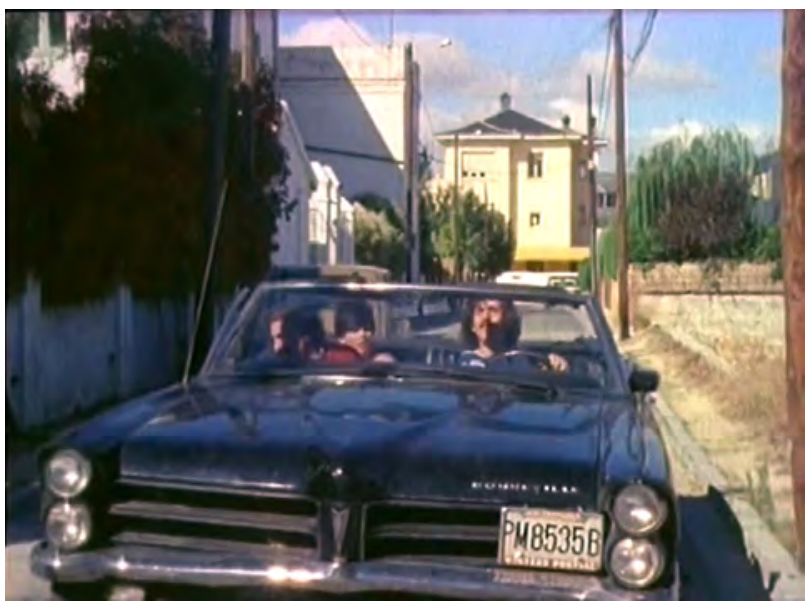

Fig. 8. Miguel y Javier de viaje por Andalucía en Pontiac en Corridas de alegría.

el rock (andaluz). Miguel (Miguel Ángel Iglesias), un convicto fugado de la cárcel, y Javier (Javier García Pelayo), un trilero, viajan en un Pontiac Bonneville por Andalucía en busca de la información necesaria para poder rescatar a la novia de Miguel, retenida por un mafioso de la zona (fig. 8). Un revestimiento genérico anecdótico y una carga erótica mucho más explícita sirven para dotar de mayor comercialidad a un film que construye un discurso sobre la realidad andaluza del momento focalizando su ficción en personajes cotidianos o populares ${ }^{23}$.

En cualquier caso, son relativamente numerosos los títulos del cine español de la Transición en los que predomina el viaje por carretera y/o el constante deambular de unos personajes que, de una u otra forma, buscan nuevos horizontes porque se hallan en una encrucijada, como Tiempos de Constitución (Rafael Gordon, 1978), Las verdes praderas (José Luis Garci, 1979) o Deprisa deprisa (Carlos Saura, 1980). En Tiempos de Constitución interesa especialmente el personaje de Luisón (Paco Algora), curioso chófer (por su forma de ver la vida) que deambula de aquí para allá según el imperativo de sus ocasionales clientes. Las verdes praderas presenta a José Rebolledo (Alfredo Landa), hombre de origen humilde, casado y con dos hijos, que ha conseguido encaramarse a un puesto directivo en una compañía de seguros y se pasa el fin de semana viajando porque tiene una casa en la sierra, a dos horas de Madrid (en un arranque de sentido común, su mujer terminará quemándola). Deprisa deprisa trata sobre la vida de los jóvenes delincuentes de Villaverde (Madrid), una vida plagada de componentes míticos que sugieren una dimensión simbólica, con un

23 Trenzado Romero, Manuel (2000): «La construcción de la identidad andaluza y la cultura de masas: el caso del cine andaluz», Revista de Estudios Regionales, núm. 58, p. 201. 
elemento-eje que le da consistencia: el automóvil (casi inseparable de sus actividades delictivas ${ }^{24}$. De los numerosos desplazamientos que aparecen en el film, cobra un especial sentido el que Pablo (José Antonio Valdelomar), Ángela (Berta Socuéllamos), Meca (Jesús Arias Aranzeque) y María (María del Mar Serrano) realizan a Almería para ver el mar, una frontera infranqueable que presagia el fatal destino que les espera.

\subsection{Carreteras democráticas}

Tras el triunfo socialista, se sigue fraguando esta cultura del viaje y de la carretera, en paralelo al esfuerzo inversor del Estado para paliar el desajuste entre la demanda de movilidad y la escasa calidad de la oferta viaria (Plan General de Carreteras 1984-1991) ${ }^{25}$, con títulos como Escapada final (Scapegoat) (Carlos Benpar, 1985), La hora bruja (Jaime de Armiñán, 1985), Cara de acelga (José Sacristán, 1986), Rumbo Norte (José Miguel Ganga, 1986), Ladrón de chatarra (Antonio García Molina, 1986), Una nit a Casa Blanca (Antoni Martí, 1987) o Las cartas de Alou (Montxo Armendáriz, 1990). Pero sólo dos de estas películas pueden considerarse road movies en sentido estricto: Rumbo Norte, sobre las peripecias de tres personajes desarraigados (un viejo italiano, un chico y una chica) a los que el destino les confía el rumbo de un camión cargado de botellas de jerez, y Una nit a Casa Blanca, en la que una pareja de jóvenes se desplaza por las carreteras catalanas (desde Gerona al delta del Ebro) en busca de un ideal abstracto que dé sentido a sus vidas. También podrían incluirse dentro del género dos películas que se desarrollan en tierras africanas: Sahara (Antonio R. Cabal, 1984) y Luna de agosto (Juan Miñón, 1986).

El triunfo del cine español on the road se produce en la década de los 90 , coincidiendo con la proliferación de la road movie en otras cinematografías, la revitalización de los géneros populares en clave postmoderna tras la fallida experiencia legislativa de Pilar Miró y un desarrollo paralelo del road genre en la literatura espanola, con tres novelas llevadas a la pantalla: Carreteras secundarias (Ignacio Martínez de Pisón, 1995), Caidos del cielo (Ray Loriga, 1995) y Manolito on the Road (Elvira Lindo, 1998), que dieron lugar a Carreteras secundarias (Emilio Martínez Lázaro, 1997), La pistola de mi hermano (Ray Loriga, 1997) y Manolito Gafotas (Miguel

${ }^{24}$ El mismo simbolismo (aunque dotado de menos contenido poético) que se puede apreciar en los títulos de José Antonio de la Loma, verdadero precursor del cine quinqui con Perros callejeros (1976).

25 Basta reproducir un pequeño fragmento del preámbulo de la memoria que acompañaba a los Presupuestos Generales para 1981 de la Dirección General de Tráfico para hacerse cargo de la situación: «Siendo las necesidades muy superiores a los recursos asignados, éstos se han distribuido de la forma más racional posible y han tenido que quedar sin atender atenciones urgentes [...] en los últimos ańos, el estado actual de la red es altamente alarmante, necesitando refuerzo [del firme] unos 15000 kilómetros. El deterioro es fuertemente progresivo variando de un $15 \%$ en 1975 a un 41\% en 1979». FernándeZ-Laguilhoat, Enrique (1981): «El automóvil y la hacienda: un balance», XIV Symposium sobre la industria automóvil: El automóvil en la sociedad, Barcelona, Salón Internacional del Automóvil, pp. 75-76. 
Albaladejo, 1999), respectivamente ${ }^{26}$. Durante estos años se producen además profundos cambios políticos: la decadencia del PSOE, cuya hegemonía toca a su fin acosada por la falta de ideas, los escándalos de corrupción (Guerra, Roldán) y una crisis económica que incrementó espectacularmente el porcentaje de desempleo a partir de 1992; y la reorganización de la derecha, capaz de atraer no sólo a los sectores más conservadores sino también a un nutrido grupo ciudadanos desencantados (victoria del Partido Popular en las elecciones de 1996, primera alternancia política desde 1982).

De hecho, más concretamente, el cine español on the road adquiere su primera y definitiva continuidad a mediados de los 90, con una proliferación de títulos de lo más diverso: Dispara (Carlos Saura, 1993), Antártida (Manuel Huerga, 1995), La pistola de mi hermano y Fugitivas (Miguel Hermoso, 2000) entroncan directamente con la tradición norteamericana del film de fuga, en el que los protagonistas huyen de la policía o de unos malhechores; Felicidades, Tovarich (Antonio Eceiza, 1995) fusiona el universo autoral de su director con un género comercial y foráneo, presentando a unos personajes autoconscientes que se comparan con Thelma y Louise ${ }^{27}$; Suspiros de España (y Portugal) (José Luis García Sánchez, 1994) y Airbag (Juanma Bajo Ulloa, 1997) abren el ciclo de la comedia ga mberra de carretera española (a la que luego nos referiremos); Carreteras secundarias y Los años bárbaros (Fernando Colomo, 1998) ponen la road movie al servicio del revisionismo histórico (franquismo e inicios de la Transición). Como se puede ver, el fenómeno afecta por igual a veteranos (Carlos Saura, José Luis García Sánchez o Emilio Martínez Lázaro) y noveles (Ray Loriga, Manuel Huerga o Juanma Bajo Ulloa); y también incluye varias coproducciones: Dispara/Spara che ti passa, Airbag, Los años bárbaros/Les Années volées, Lisboa (Antonio Hernández, 1999) y Kasbah (Mariano Barroso, 2000) ${ }^{28}$.

Un porcentaje considerable del cine español on the road de los 80 cuenta con la presencia de mujeres como protagonistas, pero éstas siempre viajan acompañadas por hombres: A contratiempo, Rumbo Norte o Una nit a Casa Blanca. En los años 90 se va a retomar la línea abierta por Vámonos, Bárbara. El filme pionero es Dispara, en el que el protagonismo femenino (aunque en este caso se trate de una sola mujer) y la estructura de montaje alterno evocan claramente a Thelma \& Louise (Ridley

${ }^{26}$ En la película de Albaladejo aparecen episodios de diferentes novelas de Manolito, aunque el cuerpo central se basa en Manolito on the Road, que se desarrolla en la última parte de la película. El relato de Arturo Pérez-Reverte Un asunto de honor (1995), que daría lugar a Cachito (Enrique Urbizu, 1996), fue escrito pensando ya en su inmediata adaptación.

27 En este caso se trata de la curiosa pareja formada por una joven (Ruth Gabriel) y su abuelo (Paco Rabal), con lo que asistimos a una temprana incorporación de un anciano a la road movie, varios años antes del modelo canónico norteamericano (The Straight Story [Una historia verdadera, David Lynch, 1999]).

${ }^{28}$ En cualquier caso, estos cinco últimos títulos se pueden catalogar como «coproducciones (inter)nacionales», esto es: películas realizadas por un equipo técnico y artístico fundamentalmente español de genuino sabor nacional que cuentan con la aportación de capitales procedentes de otros países. PARDo, Alejandro (2007): «Coproducciones internacionales españolas: ¿estrategia financiera o expresión multicultural?», Comunicación y Sociedad, vol. xx, núm. 2, pp. 145-146. 


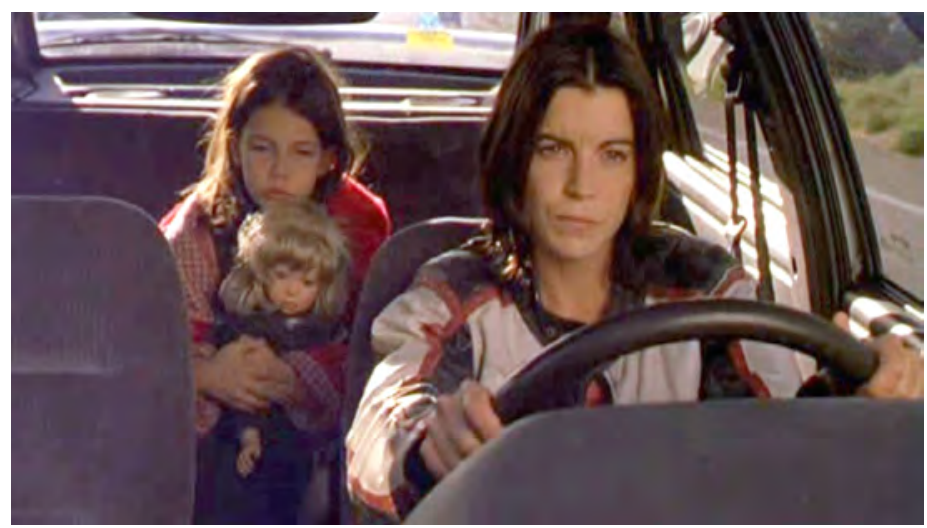

Fig. 9. La huida hacia el sur de la joven Tony con la sobrina de su novio en Fugitivas.

Scott, 1991). A la película de Saura le siguieron algunos títulos que no se amoldan completamente al género road movie, como Hola, ¿estás sola? (Icíar Bollaín, 1995) o Cuando vuelvas a mi lado (Gracia Querejeta, 1999), por lo que hay que esperar a Fugitivas, sobre la huida por carretera de una joven ratera y la sobrina de su novio (fig. 9), para que se consolide el triunfo del protagonismo femenino.

Hasta ahora el cine español on the road se había caracterizado por un predominio casi absoluto de las carreteras españolas: los camioneros de El alijo se detienen en la frontera para que los inmigrantes ilegales que transportan alcancen Francia a pie; llegar a Nápoles es el sueño del viejo Sam (Omero Antonutti) en Rumbo Norte, pero el trío protagonista nunca abandona España. Sólo Sahara y Luna de agosto se desarrollan en tierras africanas. Esta situación se invierte a partir de los 90: en Lisboa, un comerciante portugués accede a llevar a la capital portuguesa a una misteriosa mujer; en Carretera y manta (Alfonso Arandia, 1999), un convicto en fuga y su pareja cruzan la frontera con Francia para embarcarse a América; Kasbah trata sobre la búsqueda de una joven por un inhóspito Marruecos, el mismo destino de la pareja formada por el dueño de un tanatorio y una chica marroquí que trasladan el cadáver del hermano de ella (muerto cuando intentaba llegar a España en una patera) en Retorno a Hansala (Chus Gutiérrez, 2008); Marsella (Belén Macías, 2013) recrea el viaje que realiza una niña acompañada de sus dos madres (biológica y adoptiva) para conocer a su padre biológico; en Anochece en la India (Chema Rodríguez, 2013) un paralítico con una enfermedad terminal y su cuidadora rumana se desplazan por tierra a la India cruzando Europa, Irán y Pakistán. La road movie favorece, pues, el encuentro entre culturas (interculturalidad) ${ }^{29}$.

${ }^{29}$ Como caso extremo se podría citar el curioso film francés Western (Manuel Poirier, 1997), en el que Paco (Sergi López), un viajante español, y Nino (Sacha Bourdo), un inmigrante ruso, viajan juntos por la Bretaña francesa en busca del amor. 


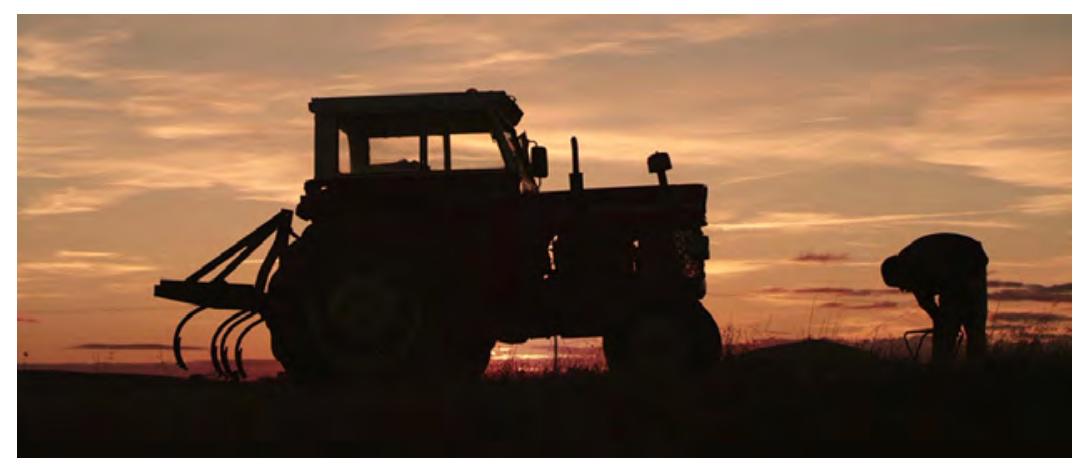

Fig. 10. Hassan se detiene a rezar en El rayo.

Durante las dos primeras décadas del siglo xxi asistimos al triunfo de algunos desarrollos temáticos y formales del género esbozados en los 90 , como la comedia gamberra de carretera y el cine de autor on the road; y a la incorporación de uno nuevo, el que fusiona la road movie con el documental. En cuanto a los personajes protagonistas, se observa la presencia recurrente de los nuevos marginados (inmigrantes, ancianos, enfermos) a imitación del cine norteamericano: un niño negro huérfano en Nos hacemos falta-Tilt- (Juanjo Giménez Peña, 2002), un inmigrante marroquí en El rayo (Fran Araujo y Ernesto de Nova, 2013) (fig. 10), una anciana cercana a los 80 y la hondureña que la cuida en Mami Blue (Miguel Ángel Calvo Buttini, 2010), un anciano que acaba de quedarse viudo en Las olas (Alberto Morais, 2011) y un enfermo terminal en El muerto y ser feliz (Javier Rebollo, 2012). Menor impacto ha tenido la incorporación de la familia a la road movie, muy presente en el cine norteamericano del siglo XXI, con tres títulos emblemáticos: Una noche en el viejo México (Emilio Aragón, 2013), coproducción con EE. UU. que explota la trama del padre que estrecha los lazos con su hijo durante un viaje; Nos hacemos falta-Tilt-y Marsella, en las que se plantean sendas alternativas a la familia tradicional fraguadas on the road (sin olvidar el antecedente de Carreteras secundarias, en la que el núcleo familiar estaba constituido por un padre y un hijo sin domicilio fijo).

La comedia gamberra de carretera española es un híbrido sin apenas preocupaciones estéticas diseñado para el consumo inmediato a partir de dos fuentes: la estela dejada por Airbag, la película más taquillera del cine español hasta que llegó Torrente, el brazo tonto de la ley (Santiago Segura, 1998); y el modelo internacional fraguado a partir de Road Trip (Viaje de pirados, Todd Phillips, 2000). Así, los ingredientes característicos del cine norteamericano, el protagonismo coral (preferentemente) masculino y el gusto por la grosería burda, son explotados en títulos como Slam (Miguel Martí, 2003), El sindrome de Svensson (Kepa Sojo, 2006) o Cromos (José Ángel Delgado, 2009); Mami Blue funciona de forma igualmente mimética al incorporar a las nuevas minorías. Como ha escrito Carmena Barrachina en relación con la comedia gamberra española: 


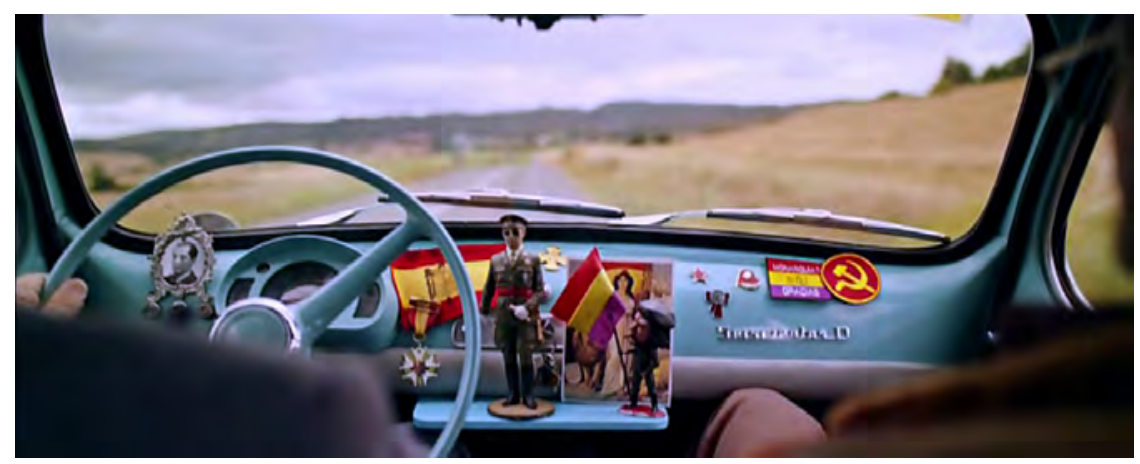

Fig. 11. La decoración interior del coche de los protagonistas de Rey gitano.

Tratándose de un subgénero inscrito en la vertiente más comercial y populista del cine que actualmente se produce en España, no sorprende que una buena parte de él se haya asentado sobre una estrategia mimética, parásita, en las antípodas de un modelo original de representación ${ }^{30}$.

En cualquier caso la comedia gamberra (de carretera) resulta un fenómeno heterogéneo que suele incorporar rasgos de la tradición cultural española (más o menos reconocibles, desarrollados con mayor o menor estridencia): Airbag se alimenta tanto del modelo norteamericano (a partir de la comedia gamberra fundacional National Lampoon's Animal House [Desmadre a la americana], John Landis, 1978) como del Berlanga postfranquista (Trilogía nacional: La escopeta nacional, 1978; Patrimonio nacional, 1981; Nacional III, 1982) y sus derivados, como Suspiros de España (y Portugal), con guion de Rafael Azcona, que a su vez podría definirse como una comedia gamberra de carretera netamente castiza; Shevernatze, una epopeya marcha atrás (Pablo Palazón, 2009) trae a la memoria el humor absurdo de La Codorniz (en la línea de El hombre que viajaba despacito); El mundo alrededor (Álex CalvoSotelo, 2006) transita por la vía de la comedia con tintes sociales, tan propia del cine español desde los 50; Rey gitano (Juanma Bajo Ulloa, 2015) intenta repetir, sin éxito, la fórmula de Airbag trazando un retrato de la Espańa de hoy, plagada de parados, embaucadores, políticos corruptos, independentistas, fachas y chonis (fig. 11).

En los últimos años diversos cineastas que apuestan por la experimentación formal y narrativa, autores noveles o ya reconocidos, han recurrido a la road movie para adaptarla a sus intereses creativos. Dies d'agost (Días de agosto, Marc Recha, 2006) documenta los días de descanso de Marc Recha acompañado de su hermano

30 Carmena Barrachina, Fernando (2006): «El caso español: préstamos, influencias y particularidades», Secuencias, núm. 24, p. 76. 
David, rompiendo la línea que separa la realidad de la ficción. El predominio del paisaje y la sucesión de personajes extrańos dinamitan la coherencia narrativa de Road Spain (Jordi Vidal, 2007) a partir del momento en que su protagonista decide recorrer España en una vieja autocaravana. Las olas basa su poética en el ritmo pausado y la práctica ausencia de palabras, en favor de los sonidos de la carretera y el campo. El hallazgo de El muerto y ser feliz consiste en que las voices over de un hombre y una mujer comenten en todo momento lo que hacen, recuerdan o viven los dos protagonistas. El rayo parte de la historia real de Hassan, un inmigrante que quiere comprar un tractor para regresar en él a Marruecos, rompiéndose nuevamente la línea que separa la realidad de la ficción (el propio Hassan se interpreta a sí mismo en la película). Huidas (Mercedes Gaspar, 2014) aborda problemas de actualidad como la violencia de género o la inmigración a través del viaje por España de China (Huichi Chiu), una fotógrafa norteamericana de origen hispano-chino que regresa para acudir al entierro de su padre y se reencuentra con sus raíces.

El desarrollo de la road movie documental o del documental road movie $e^{31}$ ejemplifica como ningún otro fenómeno el triunfo de los procesos de hibridación a los que se ven sometidas las obras audiovisuales en la actualidad (más allá del marco de la mezcla de géneros propia del cine de ficción). Forceville ha estudiado la asociación entre el documental autobiográfico o autorreferencial ${ }^{32}$ y la road movie en películas de diversas nacionalidades: Sherman's March (Ross McElwee, 1985), Life without Death (Frank Cole, 2000), De Grote Vakantie (Johan van der Keuken, 2000), Les glaneurs et la glaneuse (Los espigadores y la espigadora), Agnès Varda, 2000 y Les glaneurs et la glaneuse... deux ans après (Dos años después. Los espigadores y la espigadora), Agnès Varda, 200233. Más recientemente, Pablo Piedras ha estudiado el desarrollo de este subgénero en el ámbito latinoamericano, situándolo entre la denuncia del subdesarrollo y la vertiente autobiográfica, a través de títulos como $E l$ diablo nunca duerme (Lourdes Portillo, 1994), Return to Bolivia (Mariano Raffo, 2008), Pachamama (Eryk Rocha, 2008), Diario de uma busca (Flávia Castro, 2010) o Hija (María Paz González, 2011) ${ }^{34}$.

Centrándonos en el cine español, hay que destacar la creciente proliferación del documental road movie en los últimos años, su diversidad temática y formal

31 En el ámbito anglosajón y francófono se emplea esta terminología (documentary road movie o road movie documentary y documentaire road movie o road movie documentaire respectivamente) para catalogar los documentales que recurren a los códigos de la road movie.

32 Aquél en el que su director se convierte en personaje e indaga sobre algún aspecto relacionado en mayor o menor grado con su vida.

${ }^{33}$ Forceville, Charles (2006): «The source-path-goal schema in the autobiographical journey documentary: McElwee, Van der Keuken, Cole», New Review of Film and Television Studies, núm. 4, pp. 241-261 y ForCeville, Charles (2011): «The journey metaphor and the Source-Path-Goal schema in Agnès Varda's autobiographical gleaning documentaries», en Fludernik, Monika (ed.), Beyond Cognitive Metaphor Theory: Perspectives on Literary Metaphor, London, Routledge, pp. 281-297.

34 Piedras, Pablo (2016): «The Contemporary Documentary Road Movie in Latin America: Issues on Mobility, Displacement, and Autobiography», en Garibotto, Verónica y PÉrez, Jorge (eds.), The Latin American Road Movie, New York, Palgrave Macmillan, pp. 217-236. 


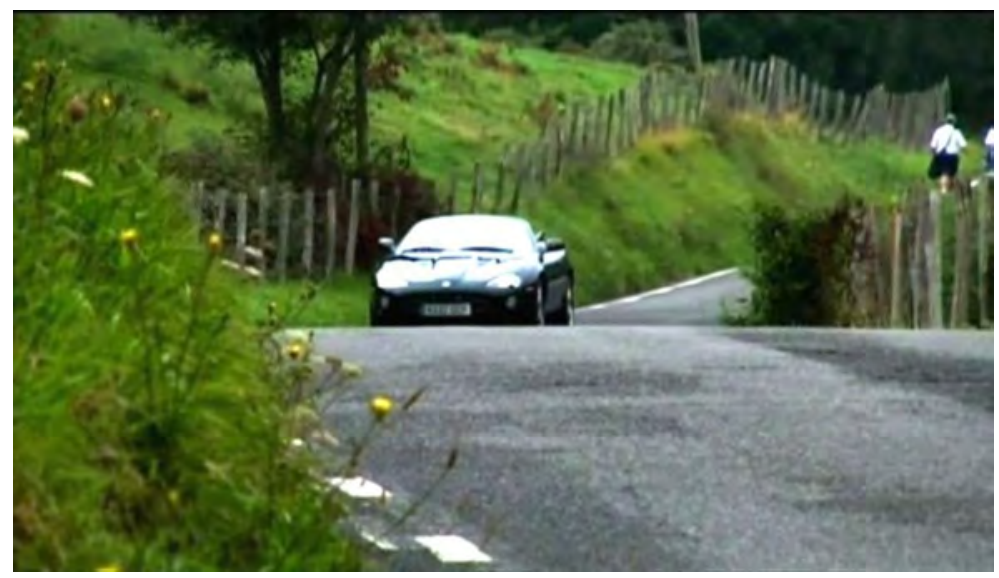

Fig. 12. Una carretera de montańa que sube y baja, como el amor, en $\mathrm{El}$ sexo de los dinosaurios.

(más allá del subtipo autobiográfico o autorreferencial) y el empleo recurrente de la etiqueta road movie en los textos promocionales de estas películas ( $\log \operatorname{lines}^{35}$, argumentos, comentarios del director, etc.). Escenario móvil (Montxo Armendáriz, 2004) defiende la universalidad del derecho a la cultura a través de un programa puesto en marcha por la Junta de Extremadura, consistente en llevar actuaciones musicales a los pueblos de menos de 2000 habitantes:

ESCENARIO MÓvil pretende ser una road-movie sosegada, tranquila, un paseo por la geografía humana, social y política de una comarca y sus gentes. Un recorrido -aquí y ahora- por sus aspiraciones, sus anhelos, sus logros, sus deseos. Y también por sus decepciones, sus sufrimientos, sus miserias y sus silencios. Un paseo por los escenarios de unas vidas sencillas, comunes, con la música de Luis [Pastor], con sus canciones, y con la voz y el testimonio de su gente, de sus paisanos, de aquellos para los que compone y canta.

Óscar Vega reivindica «... un nuevo estilo narrativo quizá más cercano al cine de ficción y que, respetando la esencia del género documental, discurre sobre una estructura metafórica de road movie» en El sexo de los dinosaurios (2007). Para lograrlo parte de una metáfora simple, el viaje en coche de sus dos únicos amigos solteros por una carretera de montaña, que le sirve de hilo conductor en su recorrido por las cuestiones esenciales de la vida: «Porque el amor nos sube y nos baja, nos conduce por la senda de la vida a través de giros, quiebros y requiebros» (fig. 12).

35 Reducción de la película a su trama esencial o high concept. Se puede traducir como frase promocional. 
American Greyhounds (Héctor Muniente y Mario Aranguren, 2010), definida por su productora y sus directores como "road movie documental», está estructurado a partir de una serie de entrevistas a personas de clase baja que, mientras viajan por EE. UU. en los míticos autobuses de la compañía Greyhound, explican sus antecedentes (de dónde vienen) y cuáles son sus proyectos de futuro (a dónde van). Tralas luces (Sandra Sánchez, 2011) recoge la historia de Lourdes y su familia, unos feriantes que recorren las carreteras del norte de España transportando una pista de coches de choque. Más de medio siglo después de haber participado como extras en el rodaje de Salomon and Sheba (Salomón y la reina de Saba), King Vidor, 1959, Juan y Serafín viajan en una furgoneta desde Cans (Galicia) hasta Roma con la intención de conocer a la protagonista de aquella película: Gina Lollobrigida en Querida Gina (Susana Sotelo, 2013). La sonrisa verdadera (Juan Rayos, 2015) relata el viaje de un niño autista ciego que, acompañado de su hermano, recorre en un tándem más de 1300 kilómetros, desde Cuenca hasta Tinerhir (Marruecos), para reencontrarse con su amiga Mati. En Proyecto USA (Miguel Herrero Herrero, 2016), promocionada como "una auténtica road movie», cuatro amigos cruzan en coche EE. UU. de costa a costa (10 000 kilómetros) recorriendo lugares míticos como las cataratas del Niágara, Monument Valley, el Gran Cañón o Hollywood.

ReCibido: diciembre-2017, ACEPTADO: abril-2018 